\title{
Enraizamento de estacas de roseira imersas em extrato aquoso de tiririca (Cyperus rotundus L.)
}

\section{Rooting of immersed seedlings roses in aqueous extract of purple tiririca (Cyperus rotundus L.)}

\author{
Marcus Vinicius Sandoval Paixão ${ }^{1 *}$, Gustavo Miranda Cremonini ${ }^{1}$, Antonio Resende \\ Fernandes $^{1}$, Rafaela Barreto Cazaroto Grobério ${ }^{1}$, Helio Pena de Faria Junior ${ }^{1}$
}

\begin{abstract}
RESUMO
Nos tubérculos de tiririca (Cyperus rotundus L.) podem ser encontradas substâncias que aceleram o enraizamento de estacas, como no caso do hormônio AIB que funciona como um hormônio vegetal, que melhora a qualidade e a uniformidade de raízes. Objetivou-se, neste estudo, avaliar o efeito de diferentes concentrações de extrato de tiririca e de tempos de imersão na promoção do enraizamento de estacas de roseira. $\mathrm{O}$ delineamento adotado foi o inteiramente ao acaso, em esquema fatorial $4 \times 4$ com oito repetições. Os tratamentos utilizados foram quatro tempos de embebição das estacas (1, 3, 5 e 10 minutos) associados a quatro concentrações de extrato de tubérculos de tiririca (10, 20, 30 e 40\%). Havia também tratamentos com quatro concentrações de ácido indol-butírico AIB (1.000 mg.kg-1; 2.000 mg.kg-1; 3.000 mg.kg-1; 4.000 $\left.\mathrm{mg} . \mathrm{kg}^{-1}\right)$ mais a testemunha. Após 60 dias avaliou-se o número de estacas enraizadas, número de brotações, número de folhas, comprimento médio da raiz e parte aérea e matéria seca de raízes e parte aérea. A imerção em extrato de tubérculo de tiririca provocou um aumento no comprimento médio de raízes e produção de matéria fresca e seca de raízes e folhas em estacas de roseira quando aplicadas nas concentrações de 30 e $40 \%$ pelos períodos de 3 e 5 minutos, sendo os resultados obtidos similares aos da utilização do AIB.
\end{abstract}

Palavras chave: Auxina; Rizogenese; Propagação vegetativa.

\begin{abstract}
In tiririca tubers (Cyperus rotundus L.), substances that accelerate rooting of cuttings can be found, as well as IBA hormone that acts like a vegetable hormone that improves the quality and uniformity of roots. The objective of this study was evaluate the effect of different tiririca extract concentrations and immersion times to promote the rooting of roseira seedlings. The adopted lineation was completely randomized in a factorial $4 \times 4$ with eight replications. the treatments were four soaking time of seedlings (1, 3, 5, and 10 minutes) associated to four purple tiririca tubers extract concentrations (10, 20, 30 and 40\%). There were four treatments indole butyric acid IBA concentrations $\left(1.000 \mathrm{mg} . \mathrm{kg}^{-1} ; 2.000 \mathrm{mg} . \mathrm{kg}^{-1} ; 3.000 \mathrm{mg} . \mathrm{kg}^{-1} ; 4.000\right.$ mg. $\mathrm{kg}^{-1}$ ) over the control. After 60 days we assessed the number of rooting, number of shoots, number of leaves, average root length and shoot and root dry matter and aerial part. The immersion in purple tiririca tuber extract caused an increase in the average length roots and fresh and dry matter production of roots and leaves on rose seedlings when applied at concentrations of 30 and $40 \%$ at periods of 3 to 5 minutes, and the results obtained are similar to IBA use.
\end{abstract}

Keywords: Auxin; Rhizogenesis; Vegetative propagation

\footnotetext{
${ }^{1}$ Instituto Federal do Espírito Santo

*E-mail: mvspaixao@gmail.com
} 


\section{INTRODUÇÃO}

A floricultura é uma atividade altamente rentável. A produção nacional de flores e plantas ornamentais garante rendimentos entre 50 e 100 mil reais por hectare, gerando, em média nacional, 3,8 empregos diretos/ha (PIZETTA, 2005). No contexto da floricultura, a rosa é considerada a principal flor de corte (LANDGRAF \& PAIVA, 2005) destacando-se como uma das principais culturas para o mercado interno e externo. A produtividade de uma roseira depende de uma série de fatores, sendo um dos importantes, é a escolha de uma boa muda.

As mudas de roseira de corte, no Brasil, são obtidas por estaquia semi-herbácea ou por enxertia de variedades híbridas sobre porta-enxertos de roseiras rústicas provenientes de estaquia que usualmente são tratadas com auxinas sintéticas.

Para facilitar e obter melhores índices de pegamento das estacas tem-se utilizado produtos à base de hormônios vegetais (ONO et al., 1994). Norberto et al. (2001) afirmam que o grupo de reguladores de crescimento usado com maior frequência é o das auxinas, que são essenciais ao processo de enraizamento por estimularem a síntese de etileno, favorecendo assim a emissão de raízes. Os reguladores de crescimento como ácido indolbutírico (AIB) é usado para melhorar o enraizamento ou nível de brotação das estacas, sendo utilizado em estacas em diversas espécies por não ser tóxico e por ser efetivo para a maioria das espécies (PIRES; BIASI, 2003).

A Cyperus rotundus L. conhecida como tiririca, é considerada como a mais importante planta daninha do mundo, devido a sua ampla destruição, capacidade de competição e agressividade, bem como a dificuldade de controle e erradicação (DURINGAM et al., 2005).

Os tubérculos de tiririca possuem atuação forte no solo, pois suas unidades de dispersão fazem com que o mesmo permaneca dormentes no solo durante grandes períodos e podem apresentar diferentes efeitos no desenvolvimento radicular de uma grande diversidade de espécies herbáceas (MUNIZ et al, 2007). Nestes tubérculos podem ser encontradas substâncias que aceleram o enraizamento de estacas de plantas, como no caso do hormônio AIB que funciona como um hormônio vegetal, que promove o enraizamento e melhora a qualidade e a uniformidade de raízes.

A aplicação de AIB vem sendo bem aproveitada para estimular o enraizamento de estacas em diversas espécies (ALVES NETO; CRUZ SILVA, 2008). Esses autores 
afirmam que há nos tubérculos de tiririca, maiores quantidades de AIB que em outras espécies herbáceas comparativamente.

Um fator que pode influenciar na formação de raízes adventícias em estacas é a concentração do regulador de crescimento utilizada (ALMEIDA et al., 2007), assim como o tempo de imersão das estacas em determinada concentração.

É de extrema importância a utilização correta das concentrações de fitorreguladores a serem aplicados na base das estacas, sendo que a concentração ideal varia com a espécie em que se está trabalhando (DIAS et al., 2012).

A pesquisa foi realizada com o objetivo de avaliar o efeito de diferentes concentrações de extrato aquoso de tubérculos de tiririca e tempos de imersão em comparação a utilização do ácido indol butírico (AIB), no estímulo ao enraizamento de estacas de roseira selvagem (Rosa canina).

\section{MATERIAIS E MÉTODOS}

O experimento foi conduzido na casa de vegetação do setor de viveiricultura do Instituto Federal do Espírito Santo (IFES-Campus Santa Teresa), com nebulização intermitente, localizado na meso região Central Espírito-Santense, cidade de Santa Teresa-ES, coordenadas geográficas 1956'12”S e 40³5’28”W, com altitude de $115 \mathrm{~m}$. O clima da região caracteriza-se como Cwa, mesotérmico, com estação seca no inverno e forte pluviosidade no verão (classificação de Köppen), com precipitação anual média de $1.404,2 \mathrm{~mm}$ e temperatura média anual de $19,9{ }^{\circ} \mathrm{C}$, com máxima de $32,8{ }^{\circ} \mathrm{C}$ e mínima de $10,6^{\circ} \mathrm{C}$ (INCAPER, 2011).

As estacas foram coletadas de ramos da variedade Rosa canina, própria para formação de porta enxerto, provenientes da própria localidade. As estacas foram preparadas com $15 \mathrm{~cm}$ de comprimento.

Os tratamentos utilizados foram quatro tempos de embebição das estacas (1, 3, 5 e 10 minutos) associados a quatro concentrações de extrato de tubérculos de tiririca (10, 20, 30 e 40\%), e quatro concentrações de ácido indol-butírico (AIB) misturado a talco neutro nas concentrações de $1.000 \mathrm{mg} . \mathrm{kg}^{-1} ; 2.000 \mathrm{mg} . \mathrm{kg}^{-1} ; 3.000 \mathrm{mg} \cdot \mathrm{kg}^{-1} ; 4.000 \mathrm{mg} . \mathrm{kg}^{-1}$ e tratamento adicional como testemunha (sem aplicação de hormônio).

Para obtenção do extrato de tiririca ( $C$. rotundus) foram utilizados tubérculos frescos, os quais foram lavados com água corrente sendo colocados para secar em folhas 
de papel. O extrato foi preparado a partir da trituração dos tubérculos em liquidificador, utilizando $200 \mathrm{ml}$ de água para cada concentração de extrato, sendo utilizadas as quantidades de 20; 40, 60 e 80 g de tiririca para obtenção das concentrações de 10, 20, 30 e $40 \%$ respectivamente. As estacas tiveram o terço basal imerso nos extratos, sendo para cada concentração testados os tempos de imersão foram de 1, 3, 5, e 10 minutos.

Para o tratamento com AIB, introduziu-se a extremidade basal da estaca em um recipiente contendo a mistura, estaqueando em tubetes com capacidade de $280 \mathrm{~mL}$, organizados em bandejas e preenchidos com substrato composto por uma mistura de areia +terra de barranco na proporção de 1:1.

O delineamento adotado foi em blocos ao acaso (DBC), em esquema fatorial $4 \times 4 \times 4$ (quatro concentrações do extrato de tiririca $\mathrm{x}$ quatro tempos de imersão $\mathrm{x}$ quatro repetições) e quatro diferentes concentrações de AIB x quatro repetições, com 40 estacas por tratamento, adicionado do tratamento testemunha sem utilização de hormônio. Cada tubete continha uma estaca, totalizando 840 estacas em todo o experimento.

As bandejas contendo as estacas foram irrigadas, diariamente, através de sistema de microaspersão, mantendo sempre a umidade do substrato a fim de favorecer as condições para o enraizamento.

Quatro meses após o estaqueamento, foram avaliadas as variáveis: número de folhas (NF); número de brotos (NB); comprimento da raiz (CR); Massa verde da parte aérea (MVA); Massa seca da parte aérea (MSA); Massa verde da raiz (MVR); Massa seca da raiz (MSR).

Os dados experimentais foram submetidos à análise de variância, atendendo as pressuposições do modelo pelo teste de Shapiro-Wilk para verificação da normalidade e as médias dos tratamentos comparadas pelo teste de Tukey em nível de 5\% de probabilidade.

\section{RESULTADO E DISCUSSÃO}

Os tratamentos com AIB, em todas as concentrações testadas, mostraram efeito positivo no enraizamento das estacas quando comparados à testemunha, obtendo-se médias estatisticamente superiores à testemunha, apresentando uma relação dosedependente, ou seja, à medida que aumenta a concentração do AIB, aumentou-se o valor em todas as variáveis avaliadas até a concentração de AIB $3.000 \mathrm{mg} \cdot \mathrm{kg}^{-1}$, estabilizando 
na concentração de AIB 4.000 mg. $\mathrm{kg}^{-1}$ com diferença estatística da concentração de 3.000 mg.kg ${ }^{-1}$, para todas as concentrações menores (Tabela 1).

Em experimento realizado por Kester et al. (1993) observou-se o pico de enraizamento de estacas de ameixeira na concentração de AIB $4.000 \mathrm{mg}$. $\mathrm{L}^{-1}$. O efeito da utilização de AIB no comprimento de raízes também foi constatado por Miranda et al. (2004) em estacas de pessegueiro. O aumento na matéria verde e seca dos tratamentos com AIB pode estar relacionada ao melhor desenvolvimento de raízes por essas estacas, de modo a melhorar a eficiência na absorção de água e nutrientes do substrato e consequente aumento na produção de parte aérea.

A partir da concentração de AIB $3.000 \mathrm{mg} \cdot \mathrm{kg}^{-1}$, não foi observado melhoria nas variáveis avaliadas, mostrando que esta concentração pode ser considerada como a melhor para enraizamento de estacas de roseira Rosa canina.

Tabela 1 - Enraizamento de estacas de roseira em diferentes concentrações de AIB

\begin{tabular}{lrrrrrrr}
\hline \multicolumn{1}{c}{ Tratamentos } & NB & NF & CR & MVF & MVR & MSF & MSR \\
\hline Testemunha & $1,7 \mathrm{c}$ & $4,9 \mathrm{~d}$ & $10,4 \mathrm{~d}$ & $2,82 \mathrm{c}$ & $5,172 \mathrm{~d}$ & $0,703 \mathrm{~b}$ & $1,302 \mathrm{c}$ \\
AIB 1.000 mg.kg-1 & $2,1 \mathrm{~b}$ & $5,7 \mathrm{c}$ & $12,7 \mathrm{c}$ & $3,23 \mathrm{~b}$ & $6,011 \mathrm{c}$ & $0,718 \mathrm{~b}$ & $1,492 \mathrm{~b}$ \\
AIB 2.000 mg.kg-1 & $2,3 \mathrm{~b}$ & $6,1 \mathrm{~b}$ & $13,6 \mathrm{~b}$ & $3,43 \mathrm{~b}$ & $7,312 \mathrm{~b}$ & $0,698 \mathrm{~b}$ & $1,519 \mathrm{~b}$ \\
AIB 3.000 mg.kg ${ }^{-1}$ & $2,9 \mathrm{a}$ & $6,6 \mathrm{a}$ & $14,1 \mathrm{a}$ & $3,92 \mathrm{a}$ & $7,903 \mathrm{a}$ & $1,345 \mathrm{a}$ & $1,882 \mathrm{a}$ \\
AIB 4.000 mg.kg-1 & $2,4 \mathrm{~b}$ & $5,2 \mathrm{~d}$ & $14,3 \mathrm{a}$ & $3,79 \mathrm{a}$ & $7,349 \mathrm{~b}$ & $1,215 \mathrm{a}$ & $1,825 \mathrm{a}$ \\
\hline
\end{tabular}

Médias seguidas da mesma letra na coluna não se diferenciam entre si pelo teste de Tukey em nível de $5 \%$ de probabilidade. $\mathrm{NB}=$ número de brotos; $\mathrm{NF}=$ número de folhas; $\mathrm{CR}=$ comprimento da raiz $(\mathrm{cm}) ; \mathrm{MVF}=$ massa verde das folhas $\left(\mathrm{g} \cdot \mathrm{pl}^{-1}\right) ; \mathrm{MVR}=$ massa verde das raízes $\left(\mathrm{g} \cdot \mathrm{pl}^{-1}\right) ; \mathrm{MSF}=$ massa seca das folhas $\left(\mathrm{g} \cdot \mathrm{pl}^{-1}\right) ; \mathrm{MSR}=$ massa seca das raízes $\left(\mathrm{g} \cdot \mathrm{pl}^{-1}\right)$.

Nos tratamentos com utilização de extrato de tubérculo de tiririca (Tabela 2), algumas combinações de concentração x período de imersão apresentou em quase todos os tratamentos médias gerais superiores à testemunha, sendo as melhores médias encontradas com as concentrações de 30 e $40 \%$ quando aplicadas por 3 e 5 minutos. As estacas do tratamento com extrato de tiririca na concentração de $30 \%$ por 5 minutos de imersão, apresentou os melhores resultados, com diferença estatística para todos os outros tratamentos. O tratamento com $40 \%$ por 5 minutos não apresentou diferença estatística para a concentração de $30 \%$ por 5 minutos de imersão nas variáveis CR, MVR. MSF e MSR, porém foi inferior estatisticamente nas variáveis NB, NF e MVF, mostrando que a produção de raízes não proporcionou produção de parte aérea como a concentração de concentração de $30 \%$ por 5 minutos de imersão. Silva (2007) em um experimento 
utilizando extrato de bulbos de tiririca, no enraizamento de estacas de pinhão-manso (Jatropha curcas L.), pôde verificar que este extrato se apresentou como um bom promotor no enraizamento das estacas, favorecendo também um bom desenvolvimento do comprimento das raízes.

Não houve resultados expressivos nas demais combinações de concentração $x$ tempo de imersão entre $10 \%$ e $20 \%$ e tempos de imersão entre 1 e 5 minutos. Tal fato aponta que o efeito da utilização do extrato dos tubérculos de tiririca é estreitamente dependente da dosagem e tempos de aplicação utilizados (Tabela 2).

Tabela 2 - Enraizamento de estacas de roseira em diferentes concentrações de extrato de tubérculo de $C$. rotundus por imersão da base das estacas em diferentes tempos

\begin{tabular}{lccccccc}
\hline Tratamentos & NB & NF & & & & \\
\hline Testemunha & $1,7 \mathrm{~d}$ & $4,9 \mathrm{fg}$ & $10,4 \mathrm{~d}$ & $2,82 \mathrm{e}$ & $5,172 \mathrm{f}$ & $0,703 \mathrm{~d}$ & $1,302 \mathrm{~cd}$ \\
$10 \% / 1 \mathrm{~min}$ & $2,1 \mathrm{c}$ & $6,3 \mathrm{~d}$ & $10,3 \mathrm{~d}$ & $4,223 \mathrm{~cd}$ & $7,234 \mathrm{~d}$ & $1,245 \mathrm{~b}$ & $1,356 \mathrm{~cd}$ \\
$20 \% / 1 \mathrm{~min}$ & $2,7 \mathrm{a}$ & $6,6 \mathrm{~cd}$ & $9,6 \mathrm{ef}$ & $4,118 \mathrm{~cd}$ & $6,567 \mathrm{e}$ & $1,234 \mathrm{~b}$ & $1,301 \mathrm{~cd}$ \\
$30 \% / 1 \mathrm{~min}$ & $2,0 \mathrm{c}$ & $6,1 \mathrm{~d}$ & $10,7 \mathrm{~d}$ & $3,875 \mathrm{~d}$ & $7,309 \mathrm{~d}$ & $1,381 \mathrm{~b}$ & $1,292 \mathrm{de}$ \\
$40 \% / 1 \mathrm{~min}$ & $2,4 \mathrm{~b}$ & $7,0 \mathrm{~b}$ & $11,9 \mathrm{c}$ & $4,660 \mathrm{~b}$ & $8,881 \mathrm{~b}$ & $1,362 \mathrm{~b}$ & $1,512 \mathrm{~b}$ \\
$10 \% / 3 \mathrm{~min}$ & $2,1 \mathrm{c}$ & $4,7 \mathrm{~g}$ & $10,5 \mathrm{~d}$ & $3,055 \mathrm{e}$ & $7,369 \mathrm{~d}$ & $0,917 \mathrm{c}$ & $1,467 \mathrm{bc}$ \\
$20 \% / 3 \mathrm{~min}$ & $2,7 \mathrm{a}$ & $6,2 \mathrm{~d}$ & $11,9 \mathrm{c}$ & $5,443 \mathrm{a}$ & $8,812 \mathrm{~b}$ & $1,703 \mathrm{a}$ & $1,399 \mathrm{~cd}$ \\
$30 \% / 3 \mathrm{~min}$ & $2,6 \mathrm{a}$ & $7,3 \mathrm{~b}$ & $12,6 \mathrm{~b}$ & $4,654 \mathrm{~b}$ & $8,838 \mathrm{~b}$ & $1,349 \mathrm{~b}$ & $1,775 \mathrm{ab}$ \\
$40 \% / 3 \mathrm{~min}$ & $2,6 \mathrm{a}$ & $5,7 \mathrm{de}$ & $12,9 \mathrm{ab}$ & $3,734 \mathrm{~d}$ & $8,891 \mathrm{~b}$ & $1,292 \mathrm{~b}$ & $1,634 \mathrm{~b}$ \\
$10 \% / 5 \mathrm{~min}$ & $2,1 \mathrm{c}$ & $4,8 \mathrm{~g}$ & $9,8 \mathrm{e}$ & $3,243 \mathrm{e}$ & $6,502 \mathrm{e}$ & $0,918 \mathrm{c}$ & $1,361 \mathrm{~cd}$ \\
$20 \% / 5 \mathrm{~min}$ & $2,2 \mathrm{c}$ & $5,3 \mathrm{ef}$ & $11,8 \mathrm{c}$ & $3,867 \mathrm{~d}$ & $8,012 \mathrm{c}$ & $1,209 \mathrm{~b}$ & $1,558 \mathrm{~b}$ \\
$30 \% / 5 \mathrm{~min}$ & $2,7 \mathrm{a}$ & $8,4 \mathrm{a}$ & $13,1 \mathrm{a}$ & $5,451 \mathrm{a}$ & $9,351 \mathrm{a}$ & $1,752 \mathrm{a}$ & $1,917 \mathrm{a}$ \\
$40 \% / 5 \mathrm{~min}$ & $2,4 \mathrm{~b}$ & $6,3 \mathrm{~d}$ & $13,0 \mathrm{a}$ & $4,749 \mathrm{~b}$ & $9,300 \mathrm{a}$ & $1,701 \mathrm{a}$ & $1,882 \mathrm{a}$ \\
$10 \% / 10 \mathrm{~min}$ & $1,2 \mathrm{e}$ & $3,8 \mathrm{~h}$ & $9,0 \mathrm{~g}$ & $2,319 \mathrm{f}$ & $6,467 \mathrm{e}$ & $0,691 \mathrm{~d}$ & $1,203 \mathrm{e}$ \\
$20 \% / 10 \mathrm{~min}$ & $1,6 \mathrm{~d}$ & $4,1 \mathrm{~h}$ & $9,3 \mathrm{fg}$ & $2,362 \mathrm{f}$ & $6,591 \mathrm{e}$ & $0,690 \mathrm{~d}$ & $1,356 \mathrm{~cd}$ \\
$30 \% / 10 \mathrm{~min}$ & $2,0 \mathrm{c}$ & $6,8 \mathrm{c}$ & $9,9 \mathrm{e}$ & $4,619 \mathrm{~b}$ & $6,593 \mathrm{e}$ & $1,120 \mathrm{~b}$ & $1,290 \mathrm{de}$ \\
$40 \% / 10 \mathrm{~min}$ & $1,2 \mathrm{e}$ & $4,2 \mathrm{~h}$ & $9,2 \mathrm{~g}$ & $2,897 \mathrm{e}$ & $6,440 \mathrm{e}$ & $0,899 \mathrm{c}$ & $1,359 \mathrm{~cd}$ \\
\hline
\end{tabular}

Médias seguidas da mesma letra na coluna não se diferenciam entre si pelo teste de Tukey em nível de $5 \%$ de probabilidade. $\mathrm{NB}=$ número de brotos; $\mathrm{NF}=$ número de folhas; $\mathrm{CR}=$ comprimento da raiz $(\mathrm{cm}) ; \mathrm{MVF}=$ massa verde das folhas $\left(\mathrm{g} \cdot \mathrm{pl}^{-1}\right) ; \mathrm{MVR}=$ massa verde das raízes $\left(\mathrm{g} \cdot \mathrm{pl}^{-1}\right) ; \mathrm{MSF}=$ massa seca das folhas $\left(\mathrm{g} \cdot \mathrm{pl}^{-1}\right) ; \mathrm{MSR}=$ massa seca das raízes $\left(\mathrm{g} \cdot \mathrm{pl}^{-1}\right)$.

A aplicação de todas as dosagens do extrato pelo período de 10 minutos provocou uma redução na média de valores em todas as variáveis avaliadas, mostrando um inicio 
de ação toxica quando aumentamos o tempo de imersão das estacas, independente da concentração de extrato de tiririca utilizada. Dias et al. (2012) constatou sintomas de toxicidade em estacas de café imersas em extrato de tiririca por 120 segundos mostrando que esta cultura é muito mais sensível que a Rosa canina.Merguro (1969) realizou experimentos que confirmaram a presença de ácido indol-acético (IAA) em tubérculos de C. rotundus podendo este exercer efeito sinergístico, ou seja, estimular efeito do AIA quando aplicado em concentrações ótimas, pois concentrações muito altas poderiam provocar toxidez às plantas. Segundo Mahmoud et al. (2009) a adição de auxinas e determinados fertilizantes em concentração desejável podem favorecer o desempenho hormonal das estacas para a emissão e obtenção de maiores números de raízes e brotos primários, induzindo a formação secundária do sistema radicular e aéreo nas fases seguintes.

Comparando o resultado obtido na testemunha sem hormônio, com o melhor resultado da aplicação de AIB (Tabela 1), com o melhor resultado obtido com imersão em extrato de tubérculo de tiririca (Tabela 2), é possível observar um acréscimo nos índices médios de número de folhas, massa verde de folhas e raiz e massa seca de folhas no tratamento com a imersão em extrato de tiririca na concentração de $30 \%$ por 5 minutos, com resultados estatisticamente superiores nas variáveis citadas em relação a utilização de AIB 3.000 mg.kg ${ }^{-1}$ (Tabela 3).

Tabela 3 - Comparação entre o melhor resultado obtido utilizando extrato de tiririca com o melhor obtido com utilização de AIB e a testemunha

\begin{tabular}{cccccccc}
\hline Tratamentos & NB & NF & & & & \\
Testemunha & $2,1 \mathrm{c}$ & $5,7 \mathrm{c}$ & $10,4 \mathrm{~b}$ & $3,23 \mathrm{c}$ & $6,011 \mathrm{c}$ & $0,703 \mathrm{c}$ & $1,332 \mathrm{~b}$ \\
$30 \% / 5 \mathrm{~min}$ & $2,7 \mathrm{a}$ & $8,4 \mathrm{a}$ & $13,1 \mathrm{a}$ & $5,45 \mathrm{a}$ & $9,351 \mathrm{a}$ & $1,752 \mathrm{a}$ & $1,917 \mathrm{a}$ \\
AIB & $2,9 \mathrm{a}$ & $6,6 \mathrm{~b}$ & $14,1 \mathrm{a}$ & $3,92 \mathrm{~b}$ & $7,903 \mathrm{~b}$ & $1,345 \mathrm{~b}$ & $1,882 \mathrm{a}$ \\
\hline
\end{tabular}

Médias seguidas da mesma letra na coluna não se diferenciam entre si pelo teste de Tukey em nível de $5 \%$ de probabilidade. $\mathrm{NB}=$ número de brotos; $\mathrm{NF}=$ número de folhas; $\mathrm{CR}=$ comprimento da raiz $(\mathrm{cm}) ; \mathrm{MVF}=$ massa verde das folhas $(\mathrm{g}) ; \mathrm{MVR}=$ massa verde das raízes $(\mathrm{g}) ; \mathrm{MSF}=$ massa seca das folhas $(\mathrm{g}) ; \mathrm{MSR}=$ massa seca das raízes $(\mathrm{g})$.

De acordo com Hartmann et al. (2017) a aplicação de uma auxina exógena pode induzir o processo da formação do primórdio radicular, uma vez que o nível endógeno de auxina não é suficiente para induzir esta resposta, mostrando ser um dos fatores limitantes. 
Com o aumento do desenvolvimento de raízes, aumenta-se também a eficiência de extração de água e nutrientes, podendo este fato ter contribuído a maior produção de matéria verde e seca. Mahmoud et al. (2009) avaliou a quantidade de raízes, brotos, brotos aéreos, testando o efeito da auxina natural extraída do tubérculo da tiririca, da auxina sintética (AIB) e do fertilizante a base de nitrogênio e zinco, na primeira fase de brotação das estacas de mandioca concluindo que o extrato do tubérculo de tiririca promove um melhor desenvolvimento das estacas. A imersão em extrato de tiririca na concentração de $30 \%$ por 5 minutos, apresentou resultados superiores ao AIB $3.000 \mathrm{mg} \cdot \mathrm{kg}^{-1}$, indicando eficiência da utilização deste hormônio natural, mostrando ser o extrato de tiririca um promissor indutor natural de enraizamento, sendo importante a realização de novos experimentos investigando novas combinações de extratos de tiririca e períodos de imersão, de modo a buscar os melhores ajustes para utilização do extrato de tiririca como indutor de enraizamento nas diferentes espécies cultivadas.

\section{CONCLUSÃO}

A imersão das estacas de roseira Rosa canina em extrato de tubérculo de tiririca $(C$. rotundus), provocou uma melhoria no enraizamento e produção de parte aérea, quando aplicadas nas concentrações de $30 \%$ pelo período de 5 minutos, sendo os resultados obtidos superiores aos da utilização do AIB, mostrando ser eficiente no enraizamento de estacas desta cultura.

A utilização desta fonte de hormônio natural aparece como uma opção para o enraizamento de estacas, merecendo uma melhor investigação para as diferentes culturas propagadas por estaquia, podendo se tornar uma opção eficiente, de baixo custo e fácil obtenção para produtores de muda ou mesmo na jardinagem.

\section{REFERÊNCIAS}

ALMEIDA, F. D. de; XAVIER, A.; DIAS, J. M. M.; PAIVA, H. N. Eficiência das auxinas (AIB e ANA) no enraizamento de miniestacas de clones de Eucalyptus cloeziana F. Muell. Revista Árvore, 31:455-463, 2007.

ALVES NETO, A.J. \&. CRUZ-SILVA, C. T. A. Efeito de diferentes concentrações de extratos aquosos de tiririca (Cyperus rotundus $L$.) sobre o enraizamento de cana-deaçúcar (Saccharum spp). Dissertação de Mestrado, Faculdade Assis Gurgacz, Cascave, 2008. $65 \mathrm{f}$. 
DIAS, J. R. M.; DA SILVA, E. D. A.; GONÇALVES, G. S.; DA SILVA, J. F.; DE SOUZA, E. F. M.; FERREIRA, E.; STACHIW, R. Enraizamento de estacas de cafeeiro imersas em extrato aquoso de tiririca. Coffee Science, v. 7, n. 3, p. 259-266, 2012.

DURIGAN, J. C.; CORREIA, N. M.; TIMOSSI, P. C. Estádios de desenvolvimento e vias de contato e absorção dos herbicidas na inviabilização de tubérculos de Cyperus rotundus. Planta Daninha, Londrina, v. 23, p. 621-626, 2005.

HARTMANN, H.T.L., KESTER, D.E., DAVIES JR, F.T., GENEVE RL; WILSON, S.B. 2017. Plant propagation: principles and practices. 9.ed., Boston: Prentice-Hall, $1024 p$.

INCAPER. Planejamento e programação de ações para Santa Teresa. Programa de assistência técnica e extensão rural PROATER, Secretaria de Agricultura, 2011.

KERSTEN, E.; LUCCHESI, A. A.; GUTIÉRREZ, L. E. Efeito do ácido indolbutírico no enraizamento de estacas de ramos de plantas de ameixeira (Prunussalicina, Lindl.). Scientia Agricola, Piracicaba, v. 50, n. 1, p. 19-26, 1993.

LANDGRAF, P. R. C.; PAIVA, P. D. O. Produção e comercialização de flores em Minas Gerais. Informe Agropecuário, Belo Horizonte, v.26, n.227, p.7-11, 2005.

MAHMOUD, T. S. Avaliação do efeito de hormônio natural, sintético e indutor no desenvolvimento da primeira fase de brotação das estacas de Manihot esculenta Crantz. Revista Raízes e Amidos Tropicais, v. 5, 2009

MIRANDA, C. S., CHALFUN, N. N. J., HOFFMANN, A., DUTRA, L. F., \& COELHO, G. V. A. Enxertia recíproca e AIB como fatores indutores do enraizamento de estacas lenhosas dos porta-enxertos de pessegueiro" Okinawa" e umezeiro. Ciência e Agrotecnologia, v. 28, n. 4, p. 778-784, 2004.

MEGURO, M. Substâncias reguladoras de crescimento em rizoma de Cyperus rotundus L. Boletim de Botânica, v.33, p.147-71 1969.

MUNIZ, F. R.; CARDOSO, M.G.; VON PINHO, E.V.R.; VILELA, M. Qualidade fisiológica de sementes de milho, feijão, soja e alface na presença de extrato de tiririca. Revista Brasileira de Sementes. 29: 195-204, 2007.

NORBERTO, P.M.; CHALFUN, N.N.J.; PASQUAL, M.; VEIGA, R.D.; PEREIRA, G.E.; MOTA, J.H. Efeito da época de estaquia e do AIB no enraizamento de estacas de figueira (Ficus carica L.). Ciência e Agrotecnologia, v.25, p.533-541, 2001.

ONO, E. O., BARROS, S. A., RODRIGUES, J. D., ONO, E. O.; BARROS, S.A.; RODRIGUES, J.D.; PINHO, S. Z. Enraizamento de estacas de Platanus acerifolia, tratadas com auxinas. Pesquisa Agropecuária Brasileira, Brasília, v. 29, n. 9, p. 1373-1380, 1994. 
PIRES, E. J. P.; BIASI, L. A. Propagação da videira. In:POMMER, C. V. (Ed.). Uva: tecnologia de produção, póscolheita, mercado. Porto Alegre: Cinco Continentes, 2003. p. 295-350

PIZETTA, P.U.C., PIVETTA, K.F.L. Produtividade de cultivares de roseira sobre diferentes porta-enxertos ou provenientes de estaquia. Revista Brasileira de Horticultura Ornamental, Campinas, v.11, n.1, p.21-28, 2005.

SILVA, C. D. Enraizamento de estacas de pinhão manso (Jatropha curcas L.) Monografia (Agronomia) - Faculdade Assis Gurgacz- FAG, Cascavel, PR. 2007. 36p.

Recebido em: 2021

Aprovado em: 2021

Publicado em: 2021 